\section{EMBRYRIDDLE}

Aeronautical University

SCHOLARLY COMMONS
Journal of Aviation/Aerospace

Education \& Research

Volume 5

Number 2 JAAER Winter 1995

Article 9

Winter 1995

\title{
The European Joint Aviation Authorities: Meeting the Challenges of International Cooperation
}

Maureen A. Pettitt

Joseph H. Dunlap

Follow this and additional works at: https://commons.erau.edu/jaaer

\section{Scholarly Commons Citation}

Pettitt, M. A., \& Dunlap, J. H. (1995). The European Joint Aviation Authorities: Meeting the Challenges of International Cooperation. Journal of Aviation/Aerospace Education \& Research, 5(2). https://doi.org/ 10.15394/jaaer.1995.1152

This Article is brought to you for free and open access by the Journals at Scholarly Commons. It has been accepted for inclusion in Journal of Aviation/Aerospace Education \& Research by an authorized administrator of Scholarly Commons. For more information, please contact commons@erau.edu. 


\title{
THE EUROPEAN JOINT AVIATION AUTHORITIES: MEETING THE CHALLENGES OF INTERNATIONAL COOPERATION
}

\author{
Maureen A. Pettitt and Joseph H. Dunlap
}

Even before the Treaty of Maastricht was signed in 1992, European leaders were looking toward a union of nation-states held together not by force but by a common goal to promote European trade, culture, economics, and technology. It is unlikely, however, that history will recount the unification of Europe as a grand and romantic revolutionary development. It has been, and continues to be, a gradual and evolutionary integration full of criticism and ethnic-based conflicts. Many questions still must be answered. The need to strike a balance between centralization and decentralization is pressing and difficult to meet.

The cooperative model envisioned by Europe's leadership is certainly not new to European civil aviation, however. Airbus Industries, the European consortium that produces air transport aircraft, for example, has been gaining ground steadily in the competitive aircraft manufacturing industry. Recent orders from Asian airlines have strengthened the consortium's position further, making it a formidable contender. Similarly, Brussels-based Eurocontrol has, since the 1960s, made significant advances in the unification of European air traffic control.

Nor is the Joint Aviation Authorities (JAA) a child of the new world order of the 1990s. The JAA began work in 1970 when it was known as the Joint Airworthiness Authorities. As this earlier name suggests, the JAA's original aim was to produce common certification codes for large airplanes and engines to support the needs of international consortia, Airbus in particular. Today, the JAA represents the civil aviation regulatory authorities of 23 European states that have agreed to cooperate in developing and implementing common standards and procedures in maintenance, licensing, and operations, as well as in establishing design and certification standards for all classes of aircraft (Joint Aviation Authorities, 1994).

These efforts are impressive examples of long-term commitment to cooperation. Figure 1 shows the complexity of the interrelationships among the European Civil Aviation Conference (ECAC), the European Union (EU), the JAA, the European Free Trade Association
(EFTA), and Eurocontrol. The EU now consists of 12 member states. EFTA is a EU partner and most EFTA members will become EU members over the next year. The ECAC is the European partner of the International Civil Aviation Organization (ICAO), which handles aviation policy and economics. The JAA works jointly with the ECAC to develop technical and licensing requirements. Eurocontrol, as previously noted, is concerned with European air traffic control.

FUNCTIONS AND ADMINISTRATION

Specifically, the JAA's objectives are (a) to ensure, through cooperation, high and consistent levels of safety within the member states; (b) to contribute to fair and equal competition within the member states; and (c) to strive for cost-effective safety and a minimum regulatory burden so the European air transportation industry can be globally competitive.

To achieve its goals, the JAA has focused on the development and adoption of Joint Aviation Requirements (JARs), the development of technical and administrative and technical procedures for implementing the JARs, and the harmonization of procedures and requirements, including cooperation with the Federal Aviation Administration (FAA).

The JAA headquarters is located in the small town of Hoofddorp in the Netherlands, a few miles east of Amsterdam's Schiphol Airport. The headquarters occupies two floors of a building in a business complex. The headquarters staff numbers 26 under a secretarygeneral responsible for divisions dealing with research, 
Figure 1

ECAC, EU, JAA, and Eurocontrol

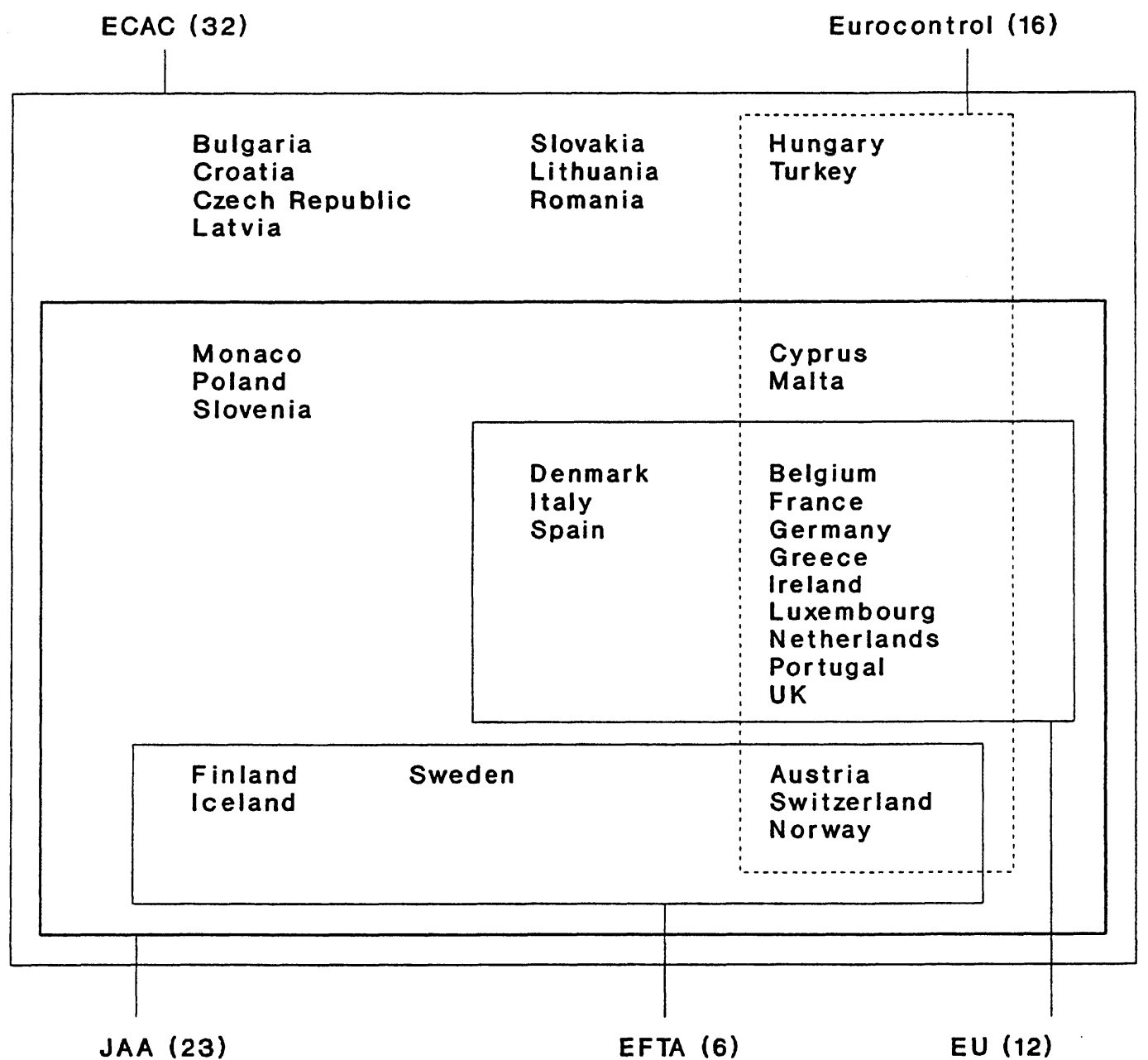

and 17 are full members. The JAA's t w o - s t a g e membership process is an interesting model. If initial, informal discussions w i t h J A A headquarters lead to a satisfactory conclusion, a candidate authority may formally apply to the JAA board for membership. The candidate member state has access to meetings, but no voting rights and no right or obligation to a $\mathrm{u}$ to $\mathrm{m}$ a $\mathrm{t}$ i c recognition of approvals by either party. Meanwhile, JAA headquarters arranges for visits by fact-finding and standardization teams.

When JAA requirements have been satisfied, a

licensing, maintenance, regulation, operations, certification, and administration. The staff is expected to grow to 36 by 1997 . The JAA's administrative structure is presented in Figure 2. Given the broad scope of these functions and the small size of the JAA staff, the national authorities provide support in approval, harmonization, standardization, certification, and safety monitoring (Joint Aviation Authorities, 1994).

MEMBERSHIP AND ORGANIZATION

Membership in the JAA is open to ECAC members. As of October 1994, 23 of the 32 ECAC nations are members of the JAA: six are candidate member states recommendation for full membership is made. JAA membership becomes official after signing the JAA Arrangements, a document originally signed by the member states in Cyprus in 1990. Although this process can be quite lengthy for some nations, the JAA believes two-stage membership is essential to safeguard the high standards and credibility of the JAA.

The JAA has developed a proposed draft treaty, now called a convention, which it hopes will give a more formal and legal status to JAA, reinforce the commitment of the member states, and aid JAA's further development. The proposed convention, completed in 
Figure 2

JAA organization

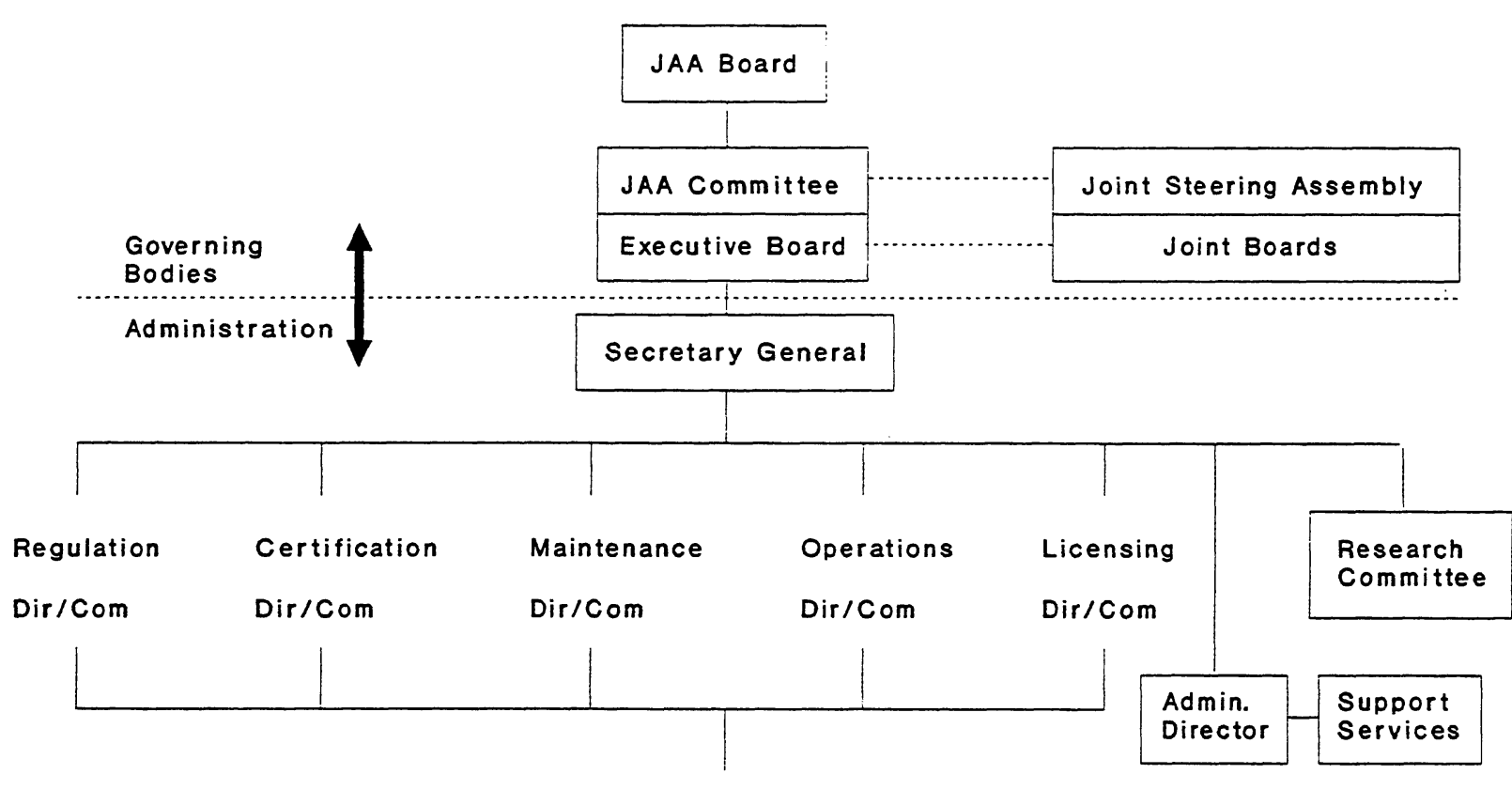

Projects, Study Groups, Teams, Etc.

November 1993, was reviewed and will be redrafted after issues such as authority, immunities, liabilities, and voting procedures are resolved.

In general, however, the convention reflects the organizational intentions and administrative relationships in which all the primary tasks are carried out by the staff of the national authorities, who also retain responsibility for the grant, variation, suspension, or revocation of approvals, licenses, and certificates. The JAA headquarters has the prime and coordinating role in regulations, harmonization, policy and procedures, and the arrangement and management of the standardization teams.

Figure 2 presents the organizational structure and relationships between the governing bodies, JAA headquarters, working groups, committees, and directors. Broad policy decisions and budget approval - \$2.82 million in 1994 with an expected budget of \$3.13 million in 1995 and $\$ 3.71$ million in 1996 - are decided by the JAA board, composed of the directors general of civil aviation of the JAA member states. The JAA is run by the JAA committee, consisting of one member from each member state. Day-to-day matters are decided by the executive board, whose six members are selected from JAA committee members.

The system is arranged to ensure that the three nations who pay the most - France, Germany, and the United Kingdom - are included in the membership of the executive committee.

Within this framework, industry is fully represented in committees and working groups that develop requirements and procedures and debate policy issues.

The JAA is funded by national contributions (85\%90\%) and income from the sale of publications and training (10\%-15\%). Each nation pays a national contribution of $0.5 \%$, which amounts to $12.5 \%$ of the funding. Additional contributions are based on the size of the country's aviation industry. As a result, each of the "largest" nations - France, Germany, and the United Kingdom - pay approximately $20 \%$ of the budget. The 
"smallest" pays about $0.6 \%$ (Joint Aviation Authorities, 1994).

\section{JAR PROGRESS REPORT}

One of the JAA's primary goals is the development, adoption, and implementation of JARs in aircraft design and manufacturing, aircraft operations and maintenance, and the licensing of aviation personnel. Given the immensity of this goal, the progress report to date is impressive.

1. Certification. The JAA's earliest efforts and greatest accomplishments have been in certification. As of October 1994, the JAA had adopted codes for the certification of large airplanes (JAR-25), small airplanes, including commuters (JAR-23), helicopters (JAR-27 and JAR-29), engines (JAR-E), auxiliary power units (JARAPU), and equipment (JAR-TSO). JAR-21 Certification Procedures for Aircraft and Related Products and Parts is ready for adoption.

Joint Type Certifications have been completed on nine aircraft, including the Airbus A-340, the McDonnell Douglas MD-11, the Jetstream 4100, and the Canadair CL600 regional jet. Joint certification programs are in progress on 10 additional aircraft, including several Airbus models, the Boeing 777-200 and 737-X, the Tupolev 204, the Citation X, and the Learjet 45. In addition, the JAA publishes Joint Implementation Procedures for certification. Developed in collaboration with industry, the procedures define the arrangements needed to achieve the mutual recognition of joint certification.

2. Maintenance. JAR-145 Approved Maintenance Organizations was adopted in January 1992. All organizations carrying out work on aircraft used for commercial air transportation - some 1,700 in Europe - are required to be approved or accepted in accordance with this JAR. The second amendment to JAR-145 provides for accepting maintenance from organizations in nations outside JAA through international maintenance agreements. Some 2,000 organizations in the United States and Canada have been accepted or are in the process of JAR-145 acceptance.

Although the JAA considers the approval of maintenance organizations the responsibility of the national authorities, an important support mechanism for the mutual acceptance of maintenance approvals is the use of Maintenance Approval Standardization Teams (MAST) that oversee the national authorities who carry out JAR-145 approvals.

3. Operations. JAR-OPS Part 1 (airplanes) and JAR-OPS Part 3 (helicopters) have been completed in draft form and circulated for comment. Adoption of these regulations is expected in April 1995, with an adoption date of April 1997. When the JAR-OPS are implemented, a system of Operations Standardization Teams (OPST) - similar to the MAST system for maintenance - will begin operating in 1997. Requirements also are being developed for simulators (JAR-SIM).

4. Flight Crew Licensing. JAR-FCL deals with the training requirements for the licensing of airplane flight crews. The latest draft has prompted many comments and, as a result, yet another major revision will be circulated in late 1994. The JAR-FCL for helicopters also will be circulated for comment in late 1994. Adoption of JAR-FCL for both airplanes and helicopters is expected in late 1995. Flight medical requirements will be adopted as a separate JAR-MED in mid-1995. The standardization team concept used in maintenance and operations will be adopted in the flight crew licensing area as well (Federal Aviation Administration, 1994).

At the headquarters in Hoofddorp, Anke Mengelberg-Thissen, the JAA's licensing director, produced a daunting stack of paper - responses to the latest draft of the JAR-FCL. It is her job to sift through all these comments and concerns of member-state aviation authorities, European airlines, military aviation interests, and private citizens, and to assist the FCL committee with the fifth draft of JAR-FCL. The committee is responsible for the content of the JARs. Mengelberg-Thissen is charged with developing implementation procedures and coordinating the standardization teams (A. Mengelberg-Thissen, personal interview, October 1993).

It is expected that the JAR-FCL will be adopted in October 1995. Pilot training schools will have two years to make the adjustments necessary to integrate the new JAA standards. Total implementation is expected to be complete by Jan. 1, 1998. 
The JAR-FCL is not currently part of the harmonization process between the FAA and the JAA, but this topic is on the priority list for the Harmonization Working Group, whose role is described below.

\section{THE HARMONIZATION PROCESS}

The European aviation community has used its past experience to forge new, cooperative structures, leading the way toward the development of a worldwide system of aviation standards. Harmonization is, however, a major undertaking that requires time, patience, and considerable communication with industry and the governments involved in the process.

As part of its overall objectives, the JAA tries to cooperate with safety regulatory authorities, especially the FAA, on the harmonization of requirements and procedures and on the certification of products and services. According to David Potter of the FAA's Air Transportation Division, the FAA has been involved in the harmonization effort for many years, particularly the early development of certification standards and, later, bilateral maintenance agreements. The motivation for instituting the harmonization process is safety, fair competition, and globalization of the industry for the benefit of the traveling public and industry.

The FAA also is involved with most of the JAA working groups. The working groups are occupied now with such tasks as establishing standards for vertical separation, training simulators, and all-weather operations. Potter said that although the FAA is not represented on all committees and working groups, the culprit is not a lack of interest, but a lack of resources. Global harmonization is an expensive venture.

It is important to note that the JAA uses a consultation process similar to the FAA's Notice of Proposed Rule Making (NPRM). The JAA's version is called Notice of Proposed Amendment (NPA). As with the FAA's system, the NPA process is cumbersome and time-consuming. For its part, the FAA assigns rulemaking harmonization initiatives to the Aviation Rulemaking Advisory Committee (ARAC). The ARAC process was established to provide advice to the FAA on all rulemaking activity.

Industry's view of harmonization, according to Bill
Schultz of the General Aviation Manufacturer's Association and ARAC committee chairman, is that it is a "process that ultimately allows the FAA and the JAA to adopt at the same time rules, practices, and procedures relative to a given topic, with the same applicability and implementation dates ... and to systematically build a uniform body of aviation regulations and guidance to uphold and progressively improve safety and ultimately achieve single certifications for airworthiness, maintenance, operations and airmen as appropriate (FAA, 1994).

The actual task of harmonization is completed by the FAR/JAR Harmonization Working Group (HWG). The HWG is one group established under both the U.S. and European systems, and its membership includes individuals from the JAA, the FAA, and U.S. and European aviation industry groups. After reaching technical agreement, the HWG prepares a full NPA/NPRM package, including economic analysis and supporting documentation. The appropriate ARAC and JAA directors approve the draft before the economic analysis, as well as the final package. The recommended NPRM is submitted to the FAA through ARAC and the recommended NPA is submitted to the JAA (Federal Aviation Administration, 1994).

\section{FUTURE DIRECTIONS}

It seems likely that the JAA/JAR and harmonization concepts could provide an effective model for wider international application. As testament, the annual harmonization meeting held in June 1994 in Boston had more than 200 attendees, including FAA personnel, JAA staff, representatives from individual European states as well as from other nations from around the globe, and a substantial number of individuals from industry. The notion of worldwide standards that allow for political differences seems valid and feasible despite the cost of this endeavor, the level of compromise required, the problems in cultural differences, and turf-protection issues.

The FAA and the JAA recognized the need to develop a strategic plan for harmonization and to establish priorities in the working groups and further establish balance between major working areas (maintenance, operations, airworthiness, and 
environmental). To provide a more comprehensive and integrated process-level management oversight, the FAA/JAA recently formed the Harmonization Management Team (HMT). The HMT consists of FAA and JAA management personnel who are charged with day-to-day oversight of the harmonization process and associated resources.

The HMT will address strategic and/or tactical planning issues, program priorities, and resource allocation concerns. The HMT will solicit input from the industry and then its recommendations will be submitted for FAA/JAA executive level review and approval. The HMT also is charged to work with the ARAC executive committee to improve linkage on the basis of ARAC proposals.

Developing a uniform body of regulations across political boundaries is a complex task. Certainly, the dedication and commitment of the JAA staff, FAA personnel, industry, and others involved with this effort should be applauded. A model and precedent is now set for other regions of the world to begin assessing the benefits of global cooperation and standardization. $\square$

Maureen Pettitt earned a Ph.D. in Education from Claremont Graduate School in California. She is on the faculty of Western Michigan University, working on a research grant.

Joseph Dunlap holds a Master's in Business Administration from City University in Seattle, Wash. He is director of the School of Aviation Sciences at Western Michigan University.

\section{REFERENCES}

Federal Aviation Administration. (1994, June). Final notes of the open sessions: 11th annual FAA/JAA harmonization meeting. Washington, DC: Author.

Joint Aviation Authorities. (1994, May). JAA: The European Joint Aviation Authorities. Hoofddorp, Netherlands: Author. $\square$ 